\title{
Deformation of the Northwestern Okhotsk Plate: How is it happening?
}

\author{
D. Hindle ${ }^{1}$, K. Fujita ${ }^{2}$, and K. Mackey ${ }^{2}$ \\ ${ }^{1}$ Albert-Ludwigs-Universität Freiburg, Geologisches Institut, Albertstr. 23b, 79104, Freiburg i. Br., Germany \\ ${ }^{2}$ Dept. Geol. Sci., Michigan State University, East Lansing, MI 48824-1115, USA
}

\begin{abstract}
The Eurasia (EU) - North America (NA) plate boundary zone across Northeast Asia still presents many open questions within the plate tectonic paradigm. Constraining the geometry and number of plates or microplates present in the plate boundary zone is especially difficult because of the location of the EU-NA euler pole close to or even upon the EU-NA boundary. One of the major challenges remains the geometry of the Okhotsk plate (OK). whose northwestern portion terminates on the EU-OK-NA triple junction and is thus caught and compressed between converging EU and NA. We suggest that this leads to a coherent and understandable large scale deformation pattern of mostly northwest-southeast trending strike-slip faults which split Northwest OK into several extruding slivers. When the fault geometry is analysed together with space geodetic and focal mechanism data it suggests a central block which is extruding faster bordered east and west by progressively slower extruding blocks until the OK plate boundary faults are encountered. Taking into account elastic loading from both the intra-OK faults and the OK-Pacific (PA) boundary reconciles geodetic motions with geologic slip rates on at least the OKNA boundary which corresponds to the Ulakhan fault.
\end{abstract}

\section{Introduction}

Northeast Russia (Fig. 1) has for a long time been identified as a region where both the number and geometry of tectonic plates and microplates are subject to uncertainty (Morgan, 1968; Seno et al., 1996; Stein and Sella, 2002). This is mostly due to the fact that the EU-NA rotation pole lies very close to their mutual plate boundary (e.g., Sella et al., 2002) with a gradual transition from active spreading along the Mid-Atlantic and Arctic (Gakkel) ridges (Eldholm et al., 1990) to mostly transpression further south in

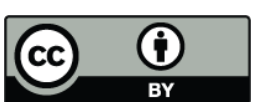

Correspondence to: D. Hindle (david.hindle@geologie.unifreiburg.de) the Central Chersky Range (Figs. 1 and 2) (Fujita et al., 2009 , this volume). As a result, a nutcracker type motion affects a roughly triangular shaped zone including the Suntar-Khayata, Kukhtuy and Central Chersky Ranges and extending southwards to the northern coastline of the Sea of Okhotsk (Figs. 1 and 2). It may also lead to varying degrees of "extrusion" of this region towards the south or southeast as it is squeezed between the two giant plates. This segment of the complex EU-NA plate boundary zone has often been considered part of the Okhotsk plate (OK) (Cook et al., 1986; Riegel et al., 1993; Seno et al., 1996; Fujita et al., 1997; Hindle et al., 2006), which extends east to the Kamchatka-Kuril subduction margin, west to Sakhalin Island and south to the Northern Sea of Japan, though historically, a range of alternative configurations of plates, blocks and microplates have been suggested for the region (Fujita et al., 2009, this volume).

The rigidity of OK, particularly its northern landward portion extending from the northern coastline of the Sea of Okhotsk to the apex formed by the EU-OK-NA triple junction, will strongly influence the kinematics of partitioning of EU-NA convergence. The northwestern portion of OK dealt with in this paper forms part of the Chersky Seismic Belt (CSB) of diffuse seismicity (Figs. 1 and 2) (Parfenov et al., 1988; Riegel et al., 1993). Seismicity of the CSB including the landward portion of OK extending from Magadan and Okhotsk on the northern coast of the Sea of Okhotsk, to the presumed EU-OK-NA triple junction is described in detail by Fujita et al. (2009, this volume). It is therefore important to understand whether the diffuse seismicity of the CSB represents an even, continuous distribution of EU-NA convergence across Northwestern OK or whether more localised slip, possibly associated with occasional large earthquakes, on larger structures, controls the kinematics of the region.

A series of end member, kinematic models for deformation partitioning across OK (Hindle et al., 2006) tested several mechanical scenarios for a distinct, Northwestern OK region undergoing compressional deformation and possible extrusion between EU and NA. The models considered the

Published by Copernicus Publications on behalf of the European Geosciences Union. 


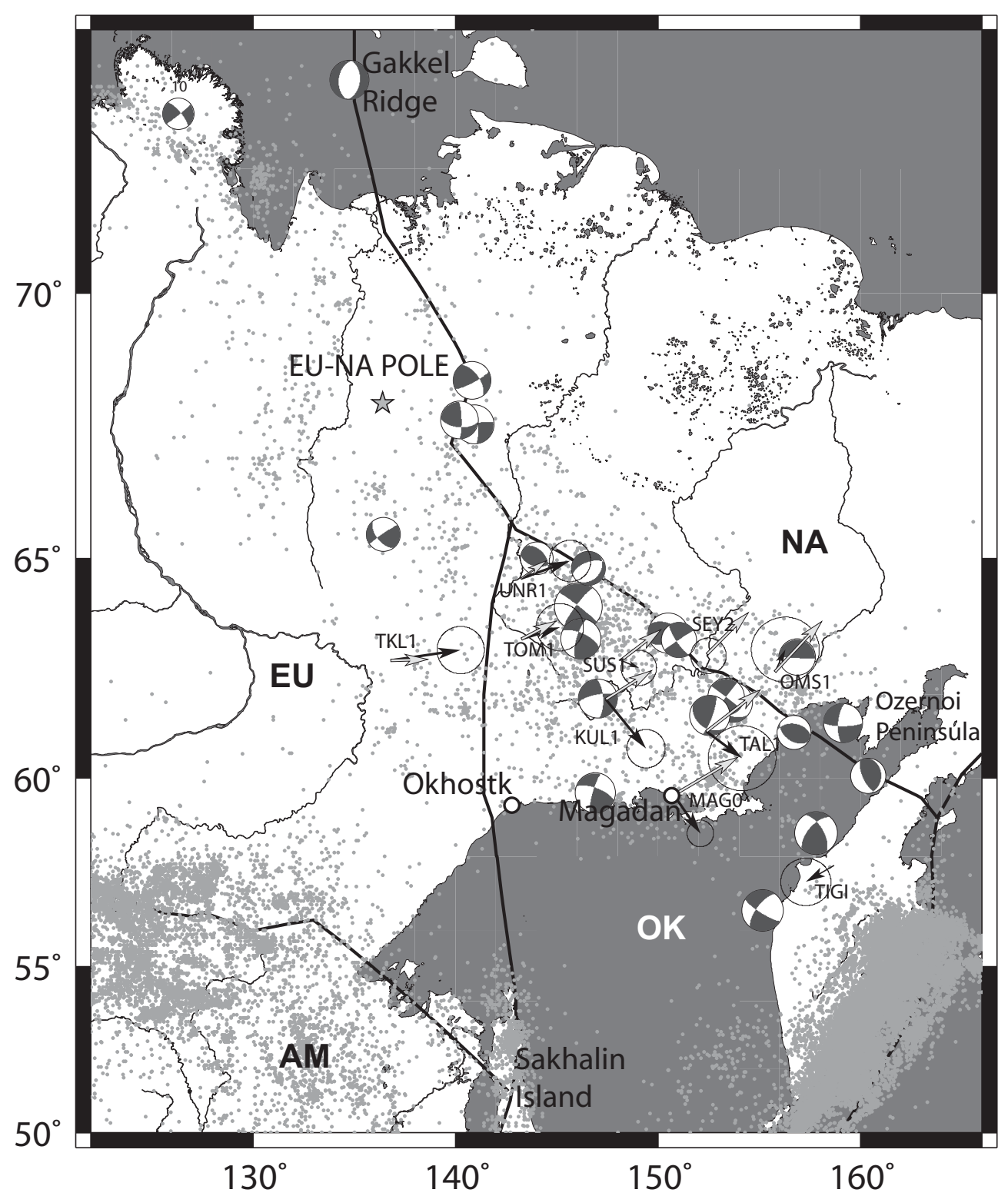

Fig. 1. Seismicity of Northeast Asia and inferred plate boundaries (heavy black lines). Major focal mechanisms, scaled for magnitude (largest event is the $M_{w} 6.4$ Artyk earthquake of 1971), small earthquake epicentres (light grey dots), GPS velocities of Steblov et al. (2003) referenced to fixed NA, with $1 \sigma$ confidence ellipses (black arrows) and station names, and EU-NA motion vectors calculated at each GPS site based on the EU-NA euler vector of Sella et al. (2002) (grey shaded arrows) are also shown.

northwestern portion of $\mathrm{OK}$ to be either an unbroken or smoothly deforming piece of lithosphere, and ignored specific geological details of the structure of the plate. In this paper, we examine in more detail the issue of how the northwestern corner of $\mathrm{OK}$ is deforming, and attempt to directly integrate geological and earthquake data into a discrete, kinematic model of this portion of the CSB.

\section{Tectonics of Northwestern Okhotsk}

\subsection{Boundaries of Northwestern Okhotsk}

In this paper, the geometry of Northwestern OK is defined following the plate boundaries suggested by Fujita et al. (1997). The OK-NA boundary is traced along the Ulakhan fault, the largest fault in the Central Chersky ranges, visible in satellite images over a distance of $\sim 1000 \mathrm{~km}$ (Parfenov et al., 1988; Imaev et al., 1994; Fujita et al., 2009) 


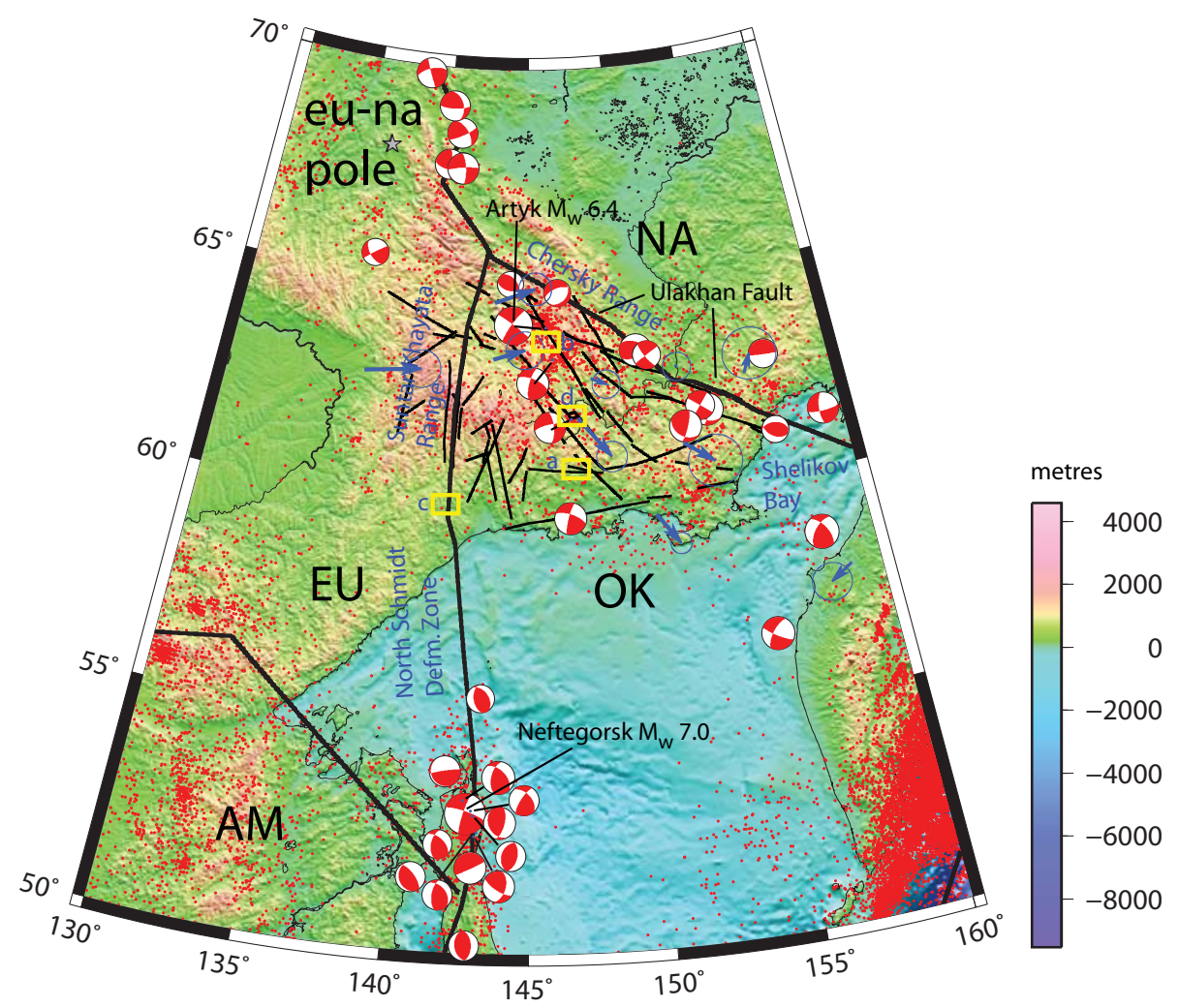

Fig. 2. Present day tectonics of the EU-NA-OK system. Figure shows major plate boundaries (heavy black lines), major focal mechanisms, scaled for magnitude (including the $M_{w} 7.0$ Neftegorsk earthquake and the $M_{w} 6.4$ Artyk earthquake), small earthquake epicentres (red dots), GPS velocities of Steblov et al. (2003) referenced to fixed NA (blue arrows) and major lineaments identified within OK. Yellow boxes delimit the approximate positions of Fig. 5a-d.

and associated with teleseismic earthquakes M4-5 and local seismicity (Fig. 2). Northeast of the Ulakhan fault, there is a noticeable drop in seismicity (Figs. 1 and 2), and the fault cuts and offsets post-Pliocene drainage networks (Krylov, 1971; Fujita et al., 2004) and Recent alluvial fans. Further east, in the northern segment of the Kamchatka peninsula, uplift of the Ozernoi peninsula (Fig. 1) suggesting considerable $(\sim 20-30 \mathrm{~mm} / \mathrm{yr})$ convergence rates has been explained by the meeting of a slowly rotating Bering Block (aseismic Komandorskii basin) (Mackey et al., 1997) and a short, extruding segment of OK (Pedoja et al., 2006). This interpretation further supports a throughgoing plate boundary between OK and NA, extending from the end of the traceable Ulakhan fault, eastwards across Shelikov Bay (Fig. 2), and into Northern Kamchatka (Fujita et al., 2009, this volume).

The OK-EU boundary is marked by a system of northsouth striking faults (Ketanda system) which crosses the CSB north and west of the settlement of Okhotsk (Figs. 1 and 2). The faults are associated with earthquakes with poorly constrained focal mechanisms indicating mostly right lateral transpression (Fujita et al., 2009, this volume). The Ketanda system reaches the Sea of Okhotsk slightly west of the settlement of Okhotsk, almost directly north of Sakhalin
Island and the site of the $M_{w} 7.0$ Neftegorsk earthquake (Fig. 2) which occurred on a NNE-SSW striking, vertical fault considered to be evidence of a plate boundary in at least the northern part of Sakhalin Island (Fournier et al., 1994; Seno et al., 1996). Transpressional flower structures are known from the sea floor south of Okhotsk in the North Schmidt Deformation Zone/Kashevarov fault (Worrall et al., 1996) (Fig. 2) but there is an absence of seismicity along this segment of the potential plate boundary (Fujita et al., 2009, this volume), except for a $M_{w} 4.8$, thrust event (11 September 2006) north of Sakhalin Island and close to the presumed trace of the boundary. This, together with the relatively continuous distribution of microseismicity westwards, across the presumed trace of the EU-OK boundary in the landward region of the Ketanda system, make its definition between Northern Sakhalin and the potential EU-OKNA triple junction more difficult. Nevertheless, seismic quiescence due to periodic locking is known along other plate boundary segments, for instance portions of the San Andreas system. It is also possible that the western boundary of OK is undergoing stable creep, perhaps enhanced by a warmer lithosphere suggested beneath the Northern Sea of Okhotsk from tomographic studies (Levin et al., 2002). 
Table 1. Strain rates calculated for the apex region of the Okhotsk plate, (from Hindle et al., 2006), giving contraction, extension magnitudes, degrees clockwise from north of contraction axis and a vertical thickening parameter calculated to conserve volume. Confidence limits for approximate $1 \sigma$ variations of EU-NA pole and angular velocity.

\begin{tabular}{lcccc}
\multicolumn{1}{c}{ Data } & $\begin{array}{c}\text { contraction } \\
\mathrm{yr}^{-1}\end{array}$ & $\begin{array}{c}\text { extension } \\
\mathrm{yr}^{-1}\end{array}$ & $\begin{array}{c}\text { cont. azi. } \\
{ }^{\circ} \text { from } \mathrm{N} .\end{array}$ & $\begin{array}{c}\text { vert. thick. } \\
\mathrm{yr}^{-1}\end{array}$ \\
\hline model & & & & \\
contr. & $-5.8 \pm 1 \mathrm{e}-9$ & $-4.9 \pm 3 \mathrm{e}-10$ & $62 \pm 1$ & $6.3 \pm 1.4 \mathrm{e}-9$ \\
smo. ext. & $-3.5 \pm 1 \mathrm{e}-9$ & $3.0 \pm 0.6 \mathrm{e}-9$ & $62 \pm 1$ & - \\
rig. ext. & - & - & - & -- \\
\hline obs. & & & & \\
GPS & $-3.7 \mathrm{e}-9$ & $6.1 \mathrm{e}-9$ & 85 & $-2.1 \mathrm{e}-9$ \\
Eq. & $-3.8 \mathrm{e}-10$ & $3.5 \mathrm{e}-10$ & 81 & $2.6 \mathrm{e}-11$ \\
\hline
\end{tabular}

\subsubsection{Active deformation}

The northwestern segment of OK is a zone of diffuse seismicity (Figs. 1 and 2). Focal mechanisms of varying reliability have been determined for a number of larger earthquakes $\left(>M_{w}\right.$ 5) and are discussed in detail in Fujita et al. (2009, this volume). The largest recorded event from the region, the $1971 M_{w} 6.4$ Artyk event (Imaev et al., 2000; Fujita et al., 2002), occurred on the Chai-Yureya fault, a major structure cutting through Northwestern OK (Figs. 2 and 5) (Imaev et al., 1994). Other events with determined focal mechanisms occur on or near to several other such structures. A combination of published moment tensor solutions and reliable focal mechanisms and magnitudes confined to within Northwestern $\mathrm{OK}$ were summed to estimate a seismic strain rate across the region by Hindle et al. (2006) (see Table 1). This gives contractional strain rates $-3.8 \times 10^{-10} \mathrm{yr}^{-1}$, directed $\sim 081^{\circ}$ as the largest principle seismic strain rate component (Fig. 3a).

As well as the seismic record from Northwestern OK, GPS velocities give a measure of internal strain across the region (Kogan et al., 2003; Steblov et al., 2003). Hindle et al. (2006) used GPS stations best able to represent strain across Northwestern OK between EU and NA to calculate a geodetic strain rate for the region. This shows uniquely extensional strain rates with largest extensional principal strain rate $\left(6.1 \times 10^{-9} \mathrm{yr}^{-1}\right.$ directed $\left.\sim 175^{\circ}\right)$, with subordinate contraction $\left(-3.7 \times 10^{-9} \mathrm{yr}^{-1}\right.$ directed $\left.\sim 085^{\circ}\right)$ (Fig. 3b). These data are based on velocity vectors uncorrected for transient, elastic displacements due to locking on either plate boundary faults or large faults within Northwestern OK itself. It has also been noted that elastic displacement due to locking of the Kamchatka subduction margin (Bürgmann et al., 2005) may subtract as much as $\sim 1-2.5 \mathrm{~mm} / \mathrm{yr}$ of motion from the southernmost stations in Northwestern OK.

\subsubsection{Deformation models}

Geometric deformation models, based on EU-NA convergence velocities along the boundaries of $\mathrm{OK}$ derived from the EU-NA euler vector of Sella et al. (2002) were constructed by Hindle et al. (2006). Three end-member modes of partitioning EU-NA convergence across Northwestern OK were tested (Fig. 3c-e, Table 1).

A pure contraction mode (Fig. 3c) where all convergence is consumed within OK by velocity gradients parallel to small circle tracks around the EU-NA pole and no material "escapes" southward yields shortening orientations similar to seismic and GPS strain, $\left(-5.8 \times 10^{-9} \mathrm{yr}^{-1}\right.$, directed $\left.\sim 062^{\circ}\right)$.

A smooth extrusion model (Fig. 3d) where the surface area of the deforming region is conserved by allowing evenly distributed area gain on the southern border of the model to compensate for area loss due to EU-NA convergence, thus modifying the pure contraction velocity field and adding a mostly south directed extrusion component gives strain rates comparable to the pure contraction scenario $\left(-3.5 \times 10^{-9} \mathrm{yr}^{-1}\right.$, directed $\left.\sim 062^{\circ}\right)$. This model velocity field also has a velocity gradient (increasing southwards) along the Ulakhan fault (identified as a candidate OKNA plate boundary). Maximum slip resolved in the direction of the Ulakhan fault is $\sim 3.0 \mathrm{~mm} / \mathrm{yr}$.

A rigid extrusion model (Fig. 3e) where Northwestern OK extrudes as a rigid whole, along the Ulakhan fault, by an amount sufficient to "fit" at the closing, southern end has no internal strain of OK though a gap (fault) is left from the triple junction southwards along the western boundary of OK. This configuration gives a constant slip rate along the Ulakhan fault of $\sim 5.5 \mathrm{~mm} / \mathrm{yr}$.

\section{Block model for Northwestern Okhotsk}

The analysis of Hindle et al. (2006) did not identify a preferred mode of accomodating EU-NA convergence across Northwestern OK, but rather suggested that a combination of all 3 end member models might be operating. Thus, a more detailed consideration of geological evidence for deformation of Northwestern OK is useful.

Russian workers first suggested the presence of a large number of linear tectonic features across the region, identifiable from a combination of satellite images, present day seismicity, geomorphology and other field data (Imaev et al., 1994; Parfenov et al., 1988). These were suggested to form a network of mostly strike-slip faults with variable senses of slip. A new interpretation of the fault network, based on topographic data, satellite images, seismicity and geomorphology (offset drainages Fujita et al., 2004) is shown in Fig. 4, where some of the major structures have been assumed to form fault-boundaries of discrete, tectonic blocks. These divide Northwestern OK into six, fault-bounded, regions with left lateral slip on block boundaries $2 / 3$ and $3 / 4$ and right 

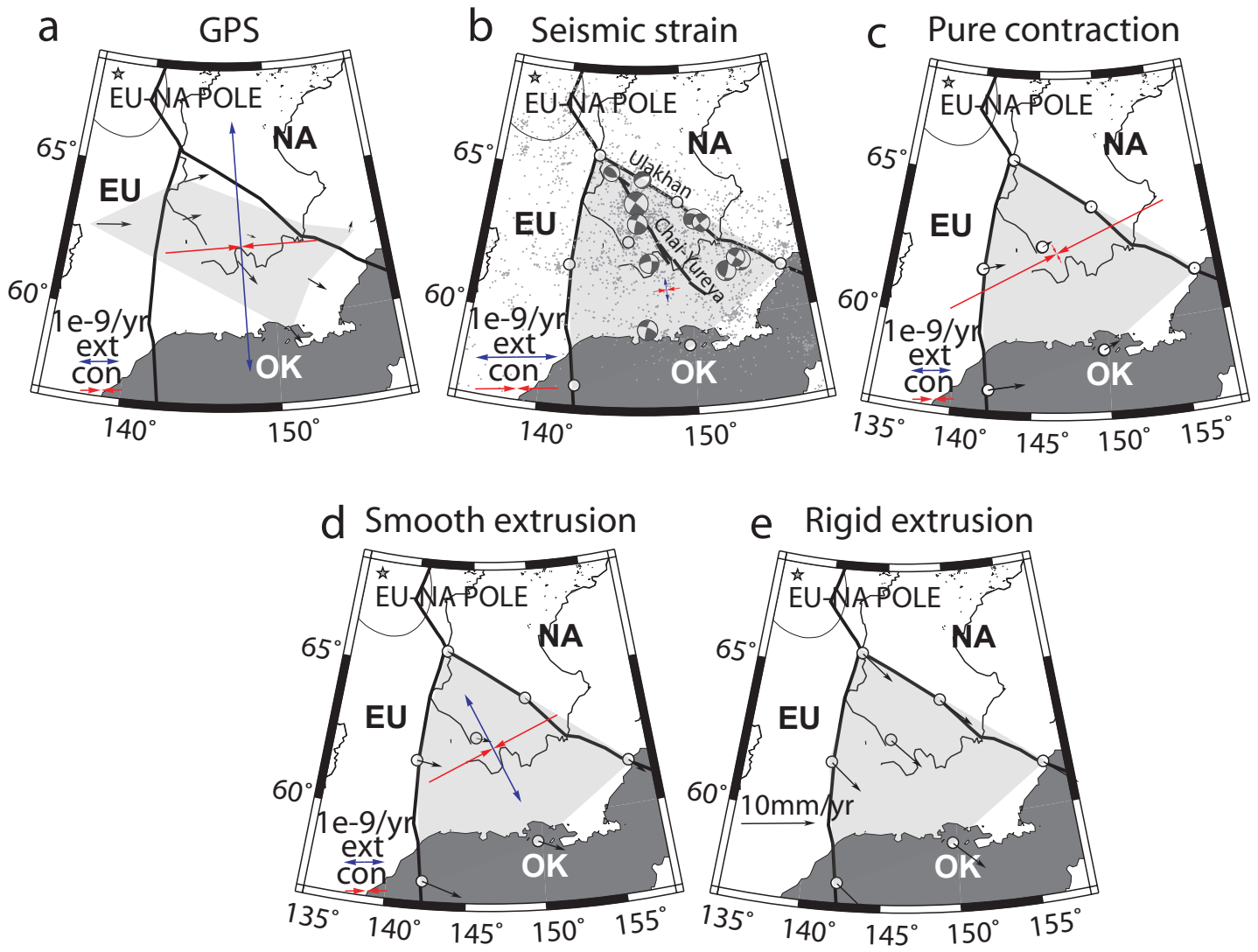

Fig. 3. Observed and modelled deformation rates across Northwestern OK (for details see Hindle et al., 2006). (a) Moment tensor sum showing focal mechanisms and strain rate axes used in calculations (b) Averaged GPS strain rate calculated across the grey shaded polygon, based on velocities of Steblov et al. (2003), vectors shown as black arrows (c) Pure contraction model where velocities (shown as black arrows at selected points) are parallel to and decrease linearly along small circle tracks around the EU-NA pole of Sella et al. (2002) (d) Smooth extrusion model with additional extrusion component to allow area conservation of OK added to contraction vectors (black arrows). (e) Rigid extrusion model, with constant velocities (black arrows) across an extruding Northwestern OK block.

lateral slip on block boundaries $4 / 5$ and $5 / 6$ and probably on part of 1/2 (Darpir) (Fig. 4). The relative slip senses imply a gradient of southward extrusion across the region, with the maximum rate reached in the central block, 4 , and decreasing from there to each plate boundary.

It is interesting to analyse the hypothetical block geometry shown in Fig. 4 which coincides with part of Northwestern $\mathrm{OK}$, in the light of both focal mechanisms and microseismicity and the recent geodetic velocity field. The 1971 Artyk $M_{w} 6.4$ earthquake and aftershock sequence (Fujita et al., 2002) (see also Fujita et al., 2009, this volume, Fig. 13) appear certain to have occurred on the Chai-Yureya fault and mark the largest recorded release of seismic energy within OK, including its presumed boundary along the Ulakhan fault. The event had a left-lateral mechanism. Offset of small rivers by up to $\sim 1 \mathrm{~km}$ has been noted along the Chai-Yureya fault, as well as an offset of $\sim 8 \mathrm{~km}$ of a Late Jurassic dolerite. The Chai-Yureya fault forms the boundary between blocks 3

www.stephan-mueller-spec-publ-ser.net/4/147/2009/ and 4 in our model (Fig. 4). Block 3 contains GPS stations SUS1 and TAL1, and block 4 contains KUL1 (Fig. 1) and GPS velocities suggest slight, left-lateral motion between the two blocks, although based on sparse data. There is also a north-to-south, increase in velocity within block 3 . This may reflect transient loading and differential locking on the block $2 / 3$ boundary fault, and hence, does not exclude a tectonically intact, rigid block 3 . The block $2 / 3$ boundary fault also has associated left-lateral focal mechanisms on or near to it. Block 1, bounded by the Darpir and Ulakhan faults, has an assumed right-lateral sense on its border with block 2, however this is not confirmed by seismic or geodetic observations. The Ulakhan fault itself forms a left-lateral boundary with all blocks bordering it, supported by evidence on a range of timescales, from post-Pliocene offset of drainage networks (this volume Fujita et al., 2004, 2009, to displacement of feeder channels in Recent alluvial fans (e.g. Seymchan-Buyunda fan) and also some earthquake focal mechanisms. The block $4 / 5$ boundary formed by the ElginOymyakon fault system was suggested to be left-lateral by 


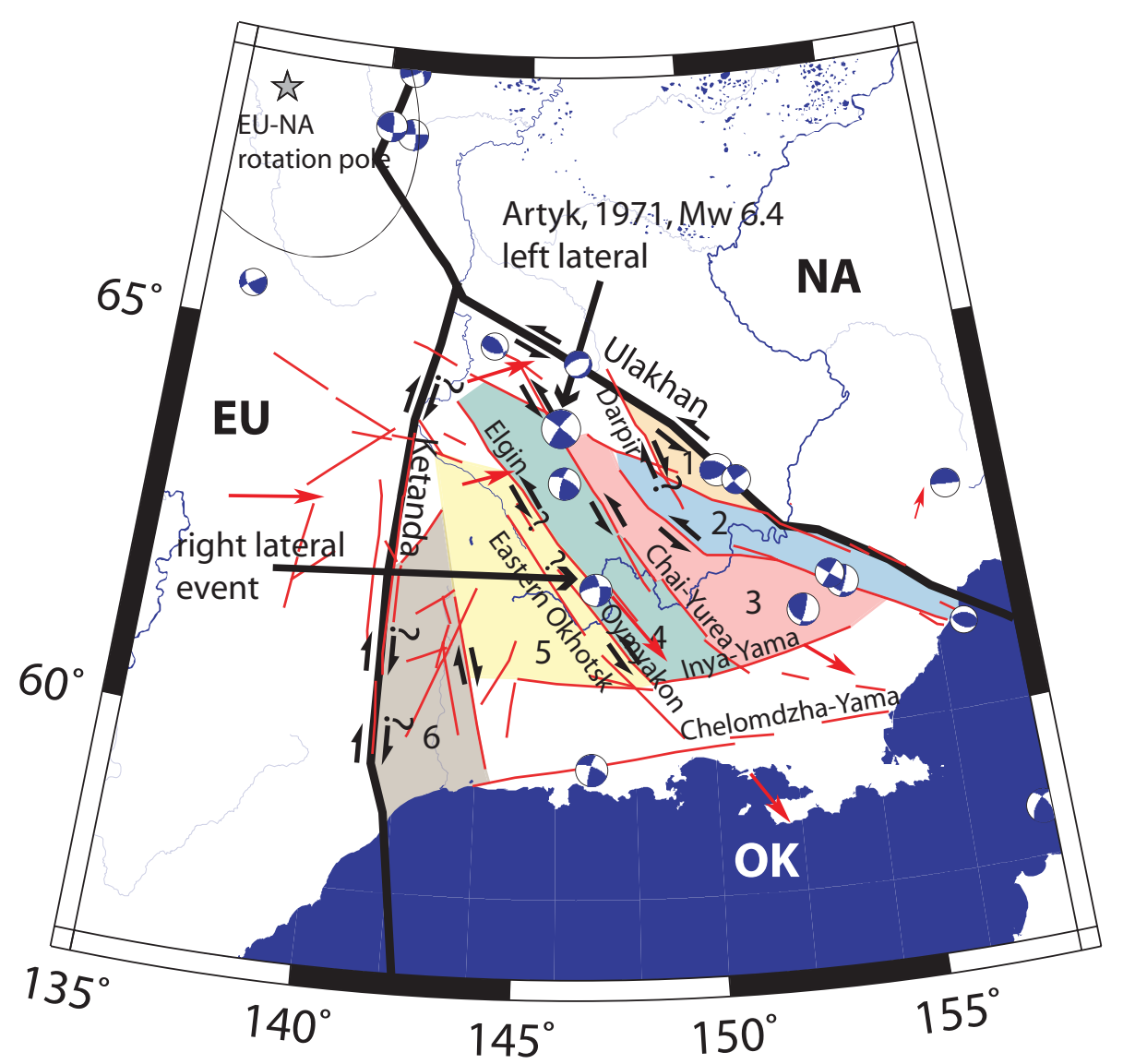

Fig. 4. Network of tectonic lineaments (mostly strike-slip faults) in Northwestern OK (after Imaev et al., 1994). Slip senses on major faults (black paired arrows) are given where possible to correspond to focal mechanisms, but otherwise follow Imaev et al. (1994). GPS vectors (red arrows) of Steblov et al. (2003) are also shown. The lineaments (red lines) have been used to divide Northwestern OK into 6 distinct blocks, mostly terminating on the Inya-Yama fault, in the south.

Imaev et al. (1994), but is associated with a right-lateral focal mechanism (Fig. 4). Only one GPS station is located within block 5 (TOM1) in its northernmost part, near the EU-OK-NA triple junction and trends almost exactly as the linear velocity from the EU-NA euler vector at this point (Fig. 1). Given the location of the GPS station in a complex region near several boundaries and a triple junction, the velocity measured may be transient and influenced by interference between elastic loading along several locked faults and boundaries.

The southern termination of the block model poses an interesting problem. The region bounded by Inya-Yama fault and the Chelomdzha-Yama fault (Fig. 4) may mark a divide between a more rigid, core region of $\mathrm{OK}$ and a softer region of warm lithosphere beneath the Sea of Okhotsk (Levin et al., 2002). The Chelomdzha-Yama fault (Fig. 4), an east-west trending lineament near the coast, has been considered a leftlateral, transpressional lineament by some Russian workers (Imaev et al., 1994). However, an apparently left-lateral focal mechanism near the trace of the lineament whose possi- ble slip vectors do not line up particularly well with the main fault trend is now thought to be associated with a subordinate, WNW trending feature (Fujita et al., 2009, this volume). The structural history of the southern onshore and offshore sea of Okhotsk region is one of Tertiary age, NNW-SSE extension (e.g., Worrall et al., 1996), and east-west trending lineaments are probable basin bounding faults from this period. Currently, limited GPS measurements suggest slight $(\sim 1 \mathrm{~mm} / \mathrm{yr})$ convergence between the fastest, southward escaping region of Northern OK within block 4, and the coastal GPS station of Magadan, meaning that the southern region delimited by the Inya-Yama and Chelomdzha-Yama faults is experiencing slight, $\sim \mathrm{N}-\mathrm{S}$ contraction, which may only have begun fairly recently. Thus, it appears that the extrusion of Northwestern OK does not end entirely before the coast of Okhotsk, but that it is most probably continued southwards into the aseismic Northern Sea of Okhotsk, which may be composed of warmer lithosphere undergoing ductile deformation, behind the still eastward retreating Kamchatka-Kuril arc. Also, we note that due to the apparently very low N-S shortening 
rates and the short ( $\sim 5 \mathrm{Ma}-10 \mathrm{Ma})$ time over which shortening is likely to have occurred, only a small amount $(\sim 1-$ $2 \mathrm{~km}$ ) of contractional deformation is likely to have accumulated across the southern region of Northwestern OK, which would remain imperceptible if spread out across many small structures across the region's width $(\sim 200 \mathrm{~km}$ in a N-S direction).

The region bordering the proposed EU-OK-NA triple junction is also not defined as a block or group of blocks. Seismic and geodetic data from this region are nevertheless interesting. The northernmost GPS station (UNR1) shows motion directed very close to the trend of the linear velocity predicted by the EU-NA euler vector of Sella et al. (2002), however, it is of greater magnitude (Fig. 1). The northernmost vector within block 5 (TOM1) is similarly directed, as already discussed. One focal mechanism, located on the northern tip of a branch of the Chai-Yureya fault gives a pure thrust solution. The combination of GPS data and seismicity in this region suggests that it may be a local manifestation of the pure contraction deformation mode of Hindle et al. (2006).

Figure 5a-d shows some examples of important Neogene structures that can be traced on satellite images. Figure 5a shows the Inya-Yama fault, which is the lineament that has the clearest expression in satellite images within OK. This lineament is not clearly associated with any earthquakes, and its linearity suggests that if it is active, it is a strike-slip fault. No clear linear feature is noticeable along the trace of the Chai-Yureya fault (Fig. 5b) although the Upper Nera basin appears to have opened on a releasing bend along the fault. The Ketanda fault (Fig. 5c) is associated with earthquakes (see Fujita et al., 2009, this volume, but its course is also not easy to distinguish from satellite images. Finally, Fig. 5d shows the southern end of the Elgin-Oymyakon system, where there may be some morphological evidence of a basin opening. In general, we note that the lack of clear satellite expression of faults may not to be a criteria for ruling out the presence of active faults as is demonstrated in particular by the Chai-Yureya fault, which is seismically active today, has traceable offsets of probably recent river systems, but remains morphologically indistinguishable.

\section{Model and GPS deformation fields and fault orientations}

In the light of the block model analysis and also the network of apparently large strike-slip faults cutting through Northwestern $\mathrm{OK}$, it is interesting to analyse the strain fields suggested by both observation and models and compare these to fault orientations. Following Holt (2000) who compared mantle anisotropy from shear wave splitting (Silver, 1996) to surface deformation measured by geodesy in Tibet, Fig. 6 shows two calculations of surface deformation fields (shear planes), based on the "smooth extrusion" model for OK
(Hindle et al., 2006) (Fig. 3d) and GPS velocities (Steblov et al., 2003). These planes are the lines of no length change in sub-regions of the two velocity fields. We compare the shear planes here to surface deformation suggested by the orientations of active faults (block boundaries). For the smooth extrusion model, one or both shear planes appear to match closely the directions of the major faults, suggesting that there may be some compatibility between the geometrically derived velocity field and the longer term strain being accumulated within Northwestern OK. The GPS derived shear planes fit less well, perhaps because this field represents an instantaneous, elastic signal of deformation that requires filtering to recover the permanent deformation it will lead to (Apel et al., 2006).

\section{Discussion}

Given the combination of evidence from GPS geodesy, seismicity and geology, a block model to explain the deformation of Northwestern OK is reasonable. Nevertheless, several issues need careful consideration. Geodetic evidence is key to establishing the relative motion of potential blocks. However, there are important transient, elastic components in this signal due to locking on the faults and elastic strain accumulation. The obvious solution to this would be a longer timespan of observations, presumably over an entire seismic cycle, which is itself an unknown quantity. Without this information, joint consideration of seismicity and geological evidence together with GPS data may give more confidence in interpreting the GPS signal. The fact that several of the relatively few focal mechanisms determined on the faults fit with the suggested relative motions from GPS may reflect that transient, elastic displacements effectively follow permanent deformation on time scales of many seismic cycles. Such behaviour has been suggested in the Andean foreland (Hindle et al., 2002; Allmendinger et al., 2005).

Our block model also leads to important questions about the plate boundary itself, particularly OK-NA formed by the Ulakhan fault. It is currently believed that the Ulakhan fault has longer term ( $\sim 3-5 \mathrm{Ma}$ ) slip rates of $\sim 5 \mathrm{~mm} / \mathrm{yr}$ (Hindle et al., 2006; Fujita et al., 2009, this volume). The block model suggests a complex division of slip within Northwestern OK with a fastest extruding central region, not directly bordering NA. The magnitude of the largest geodetic displacement (KUL1, within block 4) relative to fixed NA is $\sim 4.3 \mathrm{~mm} / \mathrm{yr}$, whilst the TAL1 station (block 3 ) has a velocity magnitude of $\sim 3 \mathrm{~mm} / \mathrm{yr}$ relative to fixed NA. There are thus potential discerepancies between measured displacements and the assumed long term slip rate on the Ulakhan fault. However, as was noted by Hindle et al. (2006), a backslip model of the elastic loading from the Kamchatka subduction zone suggests that even at distances $\sim 1000 \mathrm{~km}$ away an additional $\sim 1-2.5 \mathrm{~mm} / \mathrm{yr}$ of broadly southeasterly displacement may be removed from GPS stations due to transient northwesterly 
(a)

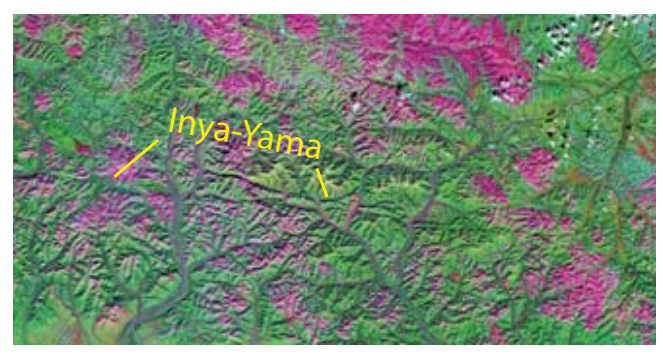

(c)

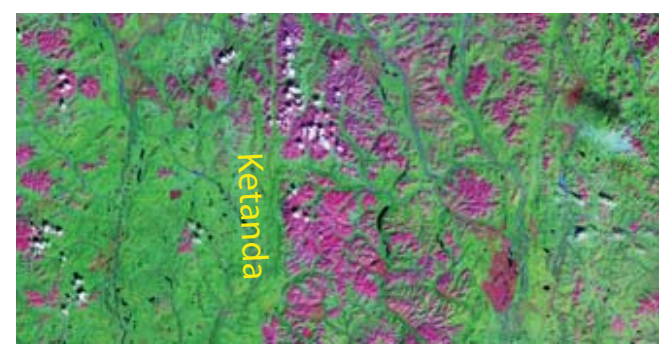

(b)

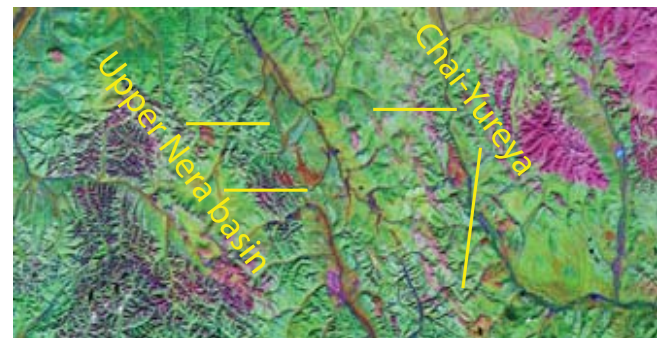

(d)

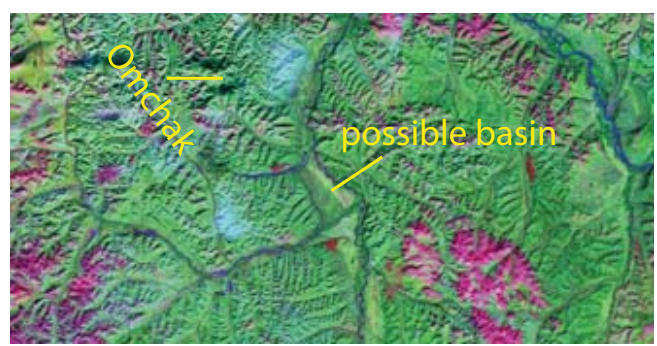

Fig. 5. Examples of the morphologic expression of faults and inferred faults from satellite images. (a) Inya-Yama fault, one of the clearest lineaments morphologically, yet not associated with modern seismicity. (b) Chai-Yureya fault, possible pull-apart basin (Upper Nera) and fault trace. Despite clear, modern seismic activity, and some evidence of recent finite offsetting of rivers, the morphological expression of the Chai-Yureya is poor. (c) Trace of the Ketanda fault, likely EU-OK boundary. (d) Possible pull-apart on the Elgin-Oymayakon fault.

(a) Smooth extrusion

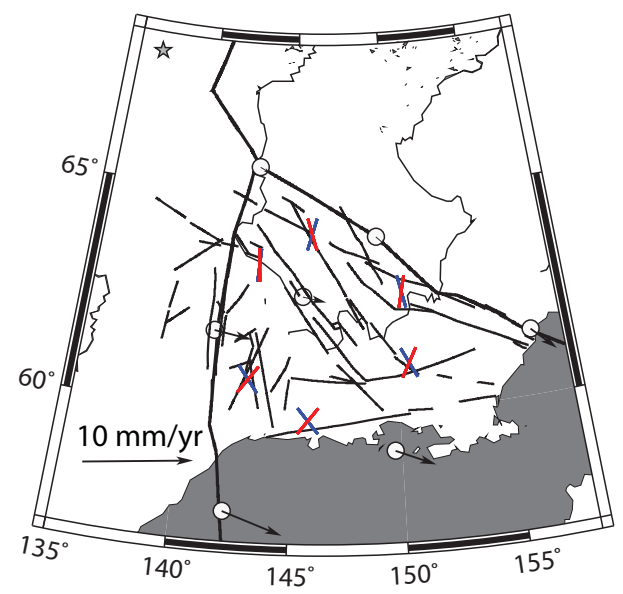

(b) GPS

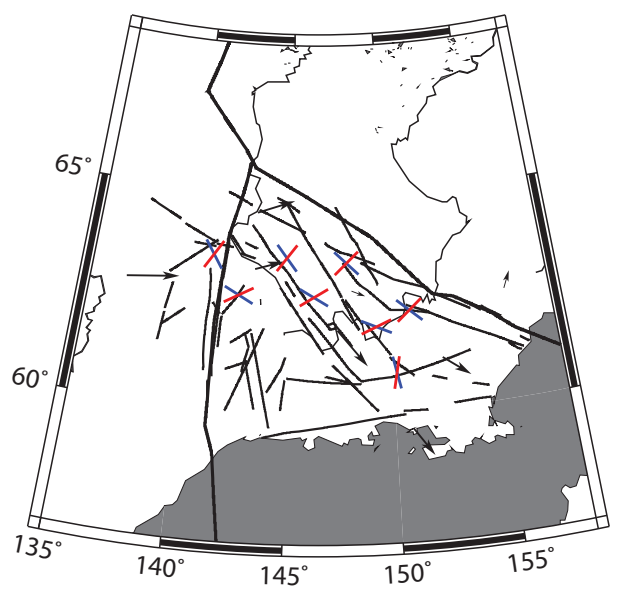

Fig. 6. Shear planes (lines of zero extension) due to deformation fields from OK (red and blue lines), calculated after the method of Holt (2000), and compared to orientations of faults (black lines) within OK (a) Based on smooth extrusion model velocity field. (b) Based on GPS velocity field. The orientation of the model shear planes in (a) matches quite well, the orientation of the major strike-slip faults suggested to be controlling deformation of the region.

pushing, which will be released over a normal seismic cycle on the OK-PA plate boundary. Adding the Kamchatka push to the TAL1 (block 3) velocity gives a net motion crudely corrected for the effects of the Kamchatka margin elastic loading, which falls very close to the likely long term slip rate of the Ulakhan fault. If indeed the TAL1 and KUL1 velocities are representative of long term displacement, this suggests an offset rate along the Chai-Yureya fault and block boundary of $\sim 1 \mathrm{~mm} / \mathrm{yr}$. However, this remains speculative and it could also be that long term offset rates between blocks 
are even lower than suggested by measured elastic displacements, and the majority of the extrusion of Northwestern OK is partitioned on the Ulakhan fault.

The long tectonic history of the region in question, linked to the Jurassic-Cretaceous inversion of Siberian platform margin sediments during the continental collision that formed the Verkhoyansk fold-thrust belt (Parfenov et al., 1995), means that some of the lineaments likely substantially predate the initiation of the modern tectonic situation discussed here. The possible offset of a dolerite body by $\sim 8 \mathrm{~km}$ along the Chai-Yureya fault may for instance be evidence of a much longer history of motion. Earlier positions of the EU-NA pole of rotation given by Gaina et al. (2002) have suggested the region would have been under similar compression to today between $\sim 20-10 \mathrm{Ma}$ for instance, which may correspond to earlier phases of slip. However, present day seismic activity and finite offset of Recent features such as fluvial systems demonstrate that a significant number of the faults are tectonically active today.

\section{Conclusions}

The possibility that Northwestern OK consists of a number of smaller, fault-bounded blocks is fairly well-supported by mostly seismological and GPS data. Based on the relatively sparse data available, the block model suggests a highest absolute rate of southward escape of block 4 , at the centre of OK, with diminishing velocities to the east and west until the OK-NA or OK-EU boundary is encountered. Absolute rates of relative motion between blocks remain undetermined, and trends in velocity are most clear between the OK-NA boundary and block 4 . The extrusion motion seems to continue into the mostly aseismic Sea of Okhotsk, but probably at a reduced rate, meaning a small amount of N-S or NW-SE contraction may occur along the coast of Okhotsk today. The fact that clearly active fault systems have sometimes very little morphological expression, suggests either that relative slip rates between blocks are low, or that the block system has been active for only a very short time.

The Ulakhan fault forming the OK-NA boundary is bounded on both sides by more or less rigid crust, which agrees with broadly constant, geological time scale displacement along its length suggested by river offset data. The relatively high magnitude of geological displacement of the Ulakhan fault, currently believed to be $\sim 5-6 \mathrm{~mm} / \mathrm{yr}$, is difficult to reconcile with the lower measured motion of portions of the interior of OK relative to NA. This may be because GPS velocities are measuring transient, elastic motions, and the velocity southwards is slowed by elastic loading from the Kamchatka subduction zone.

The local velocity differences suggested by the blocks within Northwestern OK nevertheless generate a pattern of velocities somewhat similar to a smooth extrusion model for Northwestern OK. The region closest to the EU-OK-NA triple junction behaves as if in a pure contraction deformation mode, though it is unclear what mechanism exactly leads to this.

The analysis shows the importance of joint seismic and space geodetic interpretation in understanding the functioning of plate boundary zones and we suggest more geodetic data could allow a significant test of the model we present here.

Acknowledgements. The authors thank their Russian colleagues, particularly V. Egorov, V. Imaev, L. Gunbina and B. Sedov for continuing support and discussion of research in Northeastern Russia. DH acknowledges support of the Alexander von Humboldt Stiftung. Figures were prepared using GMTv4.0 (Wessel and Smith, 1998). We are very greatful for helpful reviews by Jeremy Hourigan and an anonymous reviewer.

\section{References}

Allmendinger, R., Smalley, R., Bevis, M., Caprio, H., and Brooks, B.: Bending the Bolivian orocline in real 295 time, Geology, 33(11), 905-908, 2005.

Apel, E., Bürgmann, R., Steblov, G., Vasilenko, N., King, R., and Prytkov, A.: Independent active microplate tectonics of northeast Asia from GPS velocities and block modeling, Geophysical Research Letters, 33, L11303, doi:10.1029/2006GL026 077, 2006.

Bürgmann, R., Kogan, M., Steblov, G., Hilley, G., Levin, V., and Apel, E.: Interseismic coupling and 300 asperity distribution along the Kamchatka subduction zone., J. Geophys. Res., 110, B07405, doi:10.1029/2005JB003648, 2005.

Cook, D., Fujita, K., and McMullen, C.: Present day plate interactions in NE Asia: North American, Eurasian and Okhotsk Plates, J. Geodyn., 6(1-4), 33-51, 1986.

Eldholm, O., Karasik, M., and Reksnes, P. A.: The North American plate boundary, in: the Arctic Ocean Region, edited by: A. Grantz, L. J. and Sweeney, J. F., The Geology of North America, Geological Society of America, Boulder, Colorado, L, 171-184, 1990.

Fournier, M., Jolivet, L., Huchon, P., Sergeyev, K., and Oscorbin, L.: Neogene strike-slip faulting in Sakhalin and the Japan Sea opening, J. Geophys. Res., 99(B2), 2701-2725, 1994.

Fujita, K., Stone, D., Layer, P., Parfenov, L., and Kozmin, B.: Cooperative program helps decipher tectonics of Northeastern Russia, EOS T. Am. Geophys. Un., 78(24), p. 245, 252-253, 1997.

Fujita, K., McLean, M., Mackey, K., and Kozmin, B.: The 1971 Artyk earthquake: Is the locus of motion changing in northeast Russia, EOS T. Am. Geophys. Un., Supplement, 83, Abstract no. F1247, 2002.

Fujita, K., Sella, G., Mackey, K., Stein, S., Park, K.-D., and Imaev, V.: Relationships between seismicity and 315 GPS determined velocities in northeast Asia, EOS T. Am. Geophys. Un., 85(47) of Fall meeting suppl., Abstract no. F667, 2004.

Fujita, K., Kozmin, B., Mackey, K., Riegel, S., Imaev, V., and McLean, M.: Seismotectonics of the Chersky seismic belt, eastern Sakha Republic (Yakutia) and Magadan district, Russia, Stephan Mueller Spec. Publ. Ser., this volume, 2009.

Gaina, C., Roest, W., and Muller, R.: Late Cretaceous Cenozoic deformation of northeast Asia, Earth Planet. Sc. Lett., 197(3-4), 273-286, 2002. 
Hindle, D., Kley, J., Stein, S., Dixon, T., and Norabuena, E.: Consistency of geologic and geodetic displacements during Andean orogenesis, Geophys. Res. Lett., 29(8), 1188, doi:10.1029/2001GL013 757, 2002.

Hindle, D., Fujita, K., and Mackey, K.: Current deformation rates and extrusion of the northwestern Okhotsk plate, northeast Russia, Geophys. Res. Lett., 33, L02306, doi:10.1029/2005GL024 814,2006

Holt, W.: Correlated crust and mantle strain fields in Tibet, Geology, 28(1), 67-70, 2000.

Imaev, V., Imaeva, L., Kozmin, B., and Fujita, K.: Active faults and recent geodynamics of the Yakutian seismic belts, Geotectonics English Translation, 28, 146-158, 1994.

Imaev, V., Imaeva, L. P., and Kozmin, B.: Seismotectonics of Yakutia, GEOS, Moscow, 1st edn., 2000 (in Russian).

Kogan, M., Bürgmann, R., Vasilenko, N., Scholz, C., King, R., Ivashchenko, A., Frolov, D., Steblov, G., Kim, C. U., and Egorov, S.: The $2000 M_{w} 6.8$ Uglegorsk earthquake and regional plate boundary deformation ofSakhalin from geodetic data, Geophys. Res. Lett., 30(3), 1102, doi:10.1029/2002GL016399, 2003.

Krylov, I.: Geological factors in the course changes of a system of river valleys in mountain regions (exemplified by the headwaters of the Kolyma and Indigirka rivers), Soviet Hydrology: Selected Papers, 6, 562-565, 1971.

Levin, V., Shapiro, N., Park, J., and Ritzwoller, M.: Seismic evidence for catastrophic slab loss beneath Kamchatka, Nature, 418, 763-765, 2002.

Mackey, K., Fujita, K., Gunbina, L., Kovalev, V., Imaev, V., Kozmin, B., and Imaeva, L.: Seismicity of the Bering Strait region: Evidence for a Bering block, Geology, 25(11), 979-982, 1997.

Morgan, W. J.: Rises, trenches, great faults and crustal blocks, J. Geophys. Res., 73(6), 1959-1982, 1968.

Parfenov, L., Kozmin, B., Grinenko, O., Imaev, V., and Imaeva, L.: Geodynamics of the Chersky Seismic Belt, J. Geodyn., 9(1), 1537, 1988.
Parfenov, L., Prokopiev, A., and Gaiduk, V.: Cretaceous frontal thrusts of the Verkhoyansk fold belt, eastern Siberia, Tectonics, 14(2), 342-358, 1995.

Pedoja, K., Bourgeois, J., Pinegina, T., and Higman, B.: Does Kamchatka beong to North America? An extruding Okhotsk block suggested by coastal neotectonics of the Ozernoi Peninsula, Kamchatka, Russia, Geology, 34(5), 353-356, 2006.

Riegel, S. A., Fujita, K., Kozmin, B. M., Imaev, V. S., and Cook, D. B.: Extrusion tectonics of the Okhotsk plate, northeast Asia., Geophys. Res. Lett., 20(7), 607-610, 1993.

Sella, G. F., Dixon, T. H., and Mao, A.: REVEL: A model for Recent plate velocities from space geodesy, J. Geophys. Res., 107(B4), 2081, 10.1029/2000JB000033, 2002.

Seno, T., Sakurai, T., and Stein, S.: Can the Okhotsk plate be discriminated from the North American plate?, J. Geophys. Res., 101(B5), 11305-11315, 1996.

Silver, P. G.: Seismic anisotropy beneath the continents: Probing the depths of geology, Annu. Rev. Earth Pl. Sc., 24, 385-432, 1996.

Steblov, G. M., Kogan, M. G., King, R. W., Scholz, C. H., Bürgmann, R., and Frolov, D. I.: Imprint of the North American plate in Siberia revealed by GPS, Geophys. Res. Lett., 30(18), 1924, doi:10.1029/2003GL017805, 2003.

Stein, S. and Sella, G. F.: Plate boundary zones: Concepts and approaches, in: Plate Boundary Zones, AGU Geodynamics Series, edited by: Stein, S. and Freymuller, G., Washington, DC, 30, 1-26, doi:10/1029/030GD01, 2002.

Wessel, P. and Smith, W. H. F.: New, improved version of Generic Mapping Tools released, EOS T. Am. Geophys. Un., 79(47), 579 pp., 1998.

Worrall, D., Kruglyak, V., Kunst, F., and Kuznetsov, V.: Tertiary tectonics of the Sea of Okhotsk, Russia: Far-field effects of the India-Eurasia collision, Tectonics, 15(4), 813-826, 1996. 